\title{
BACTERIAL PATHOGENS ISOLATED FROM SURGICAL SITE INFECTIONS AND THEIR ANTIBIOTIC SUSCEPTIBILITY
}

\author{
AIDA PETCA ${ }^{1 \#}$, SILVIUS NEGOIȚ $\breve{~}^{2 \#}$, RĂZVAN-COSMIN PETCA ${ }^{3 \#}$, ANDREEA \\ BORISLAVSCHI ${ }^{1 *}$, IOANA GABRIELA CALO ${ }^{1}$, VALENTINA GABRIELA POPESCU ${ }^{4}$, \\ RUXANDRA DIANA SINESCU ${ }^{5}$
}

\author{
${ }^{I}$ Department of Obstetrics and Gynaecology, Elias University Emergency Hospital, "Carol Davila” University of Medicine \\ and Pharmacy, Bucharest, Romania \\ ${ }^{2}$ Department of Anaesthesiology and Critical Care, Elias University Emergency Hospital, "Carol Davila" University of \\ Medicine and Pharmacy, Bucharest, Romania \\ ${ }^{3}$ Department of Urology, "Prof. Dr. Th. Burghele" Clinical Hospital, "Carol Davila” University of Medicine and Pharmacy, \\ Bucharest, Romania \\ ${ }^{4}$ Department of Vascular Surgery, Elias University Emergency Hospital, Bucharest, Romania \\ ${ }^{5}$ Department of Plastic Surgery \& Reconstructive Microsurgery, Elias University Emergency Hospital, "Carol Davila" \\ University of Medicine and Pharmacy, Bucharest, Romania
}

*corresponding author: andreea.borislavschi@gmail.com

${ }^{\#}$ Authors with equal contribution.

Manuscript received: January 2021

\begin{abstract}
The increased reservoir of pathogenic bacteria sheltered in hospitals is the cause of various types of nosocomial infections and represents one of the major health problems. Surgical site infections (SSIs) count for $14-16 \%$ of all hospital-acquired infections (HAI) and represent the $3^{\text {rd }}$ most occurring nosocomial infections and the $3^{\text {rd }}$ most expensive HAI. We present a germ pattern (on 92 strains), located in post-operative dehiscence sites - treated with vacuum-assisted closure, in failed per secundam suture. The most common pathogens were $E$. coli - $18.47 \%$ (76.47\% multi-drug resistant - MDR), Pseudomonas aeruginosa - 16.30\% (33.33\% MDR) and Enterococcus faecalis - 15.21\%. Acinetobacter baumannii (100\%) and Klebsiella pneumoniae $(88.88 \%$ ) also showed multi-drug resistance. Gentamicin, amikacin and carbapenems (> 50\% sensibility) are eligible for treating SSIs, whereas cephalosporins have a higher resistance rate (> 50\%). Knowledge of resistance patterns in SSIs is recommendable to ensure proper empirical treatment.
\end{abstract}

\section{Rezumat}

Rezervorul crescut de bacterii patogene din spitale reprezintă cauza multiplelor tipuri de infecții nosocomiale, fiind una dintre problemele majore de sănătate. Infecțiile plăgilor postoperatorii ocupă locul 3 atât ca incidență cât și ca cea mai costisitoare infecție nosocomială. Studiul prezintă tiparul de rezistență a unei serii de patogeni (92 de bacterii) din plăgile postoperatorii dehiscente, pentru care s-a aplicat sistemul de terapie cu presiune negativă, după eșuarea suturii per secundam. Cele mai frecvente bacterii au fost $E$. coli - 18,47\% (76,47\% multirezistent), Pseudomonas aeruginosa - 16,30\% (33,33\% multirezistent) și Enterococcus faecalis - 15,21\%. În privința multirezistenței bacteriene s-au evidențiat și Acinetobacter baumannii (100\%), Klebsiella pneumoniae (88,88\%). Tratamentul cu gentamicină, amikacină şi clasa carbapenemelor (sensibilitate $>50 \%$ fiecare) pot fi o soluție; terapia cu cefalosporine nu trebuie indicată de primă intenție (rezistență $>50 \%$ ). Cunoașterea tiparelor de rezistență în infecțiile plăgilor operatorii este recomandabilă pentru a asigura un tratament empiric adecvat.

Keywords: pathogens, MDR bacterial pathogens, surgical site infections, vacuum-assisted closure, hospital-acquired infections

\section{Introduction}

The increased reservoir of pathogenic bacteria sheltered in hospitals is the cause of various types of nosocomial infections, called hospital-acquired infections (HAI), and represent one of the world's major health problems. Surgical site infections (SSIs) count for $14-16 \%$ of all HAI and represent the $3^{\text {rd }}$ most occurring nosocomial infections and the $3^{\text {rd }}$ most expensive HAI. It has been estimated that the hospital pays $\$ 20,785$ per case $[25$, 40]. For example, in some countries, SSI prevalence was reported as $44.1 \%$ [22]. It represents a significant health problem, undoubtedly under-reported with a considerable impact: increases morbidity and mortality, delays hospital discharge, or requires readmission, further surgeries, with a suboptimal aesthetic outcome and low quality of life.

SSIs are becoming a challenge to treat due to the emerge of multi-drug resistant (MDR) bacterial pathogens. These cases associate an increased length of hospital stay, a 2-to-11-fold rise in the risk of mortality, and also surges the economic burden [4]. The battle between germs and their susceptibility to antibiotics is still a worldwide health problem. HAI by resistant bacteria 
worsens the patients' conditions. Antibiotic resistance can affect any person at any stage of life, especially those with a weakened immune system. Besides, it threatens modern healthcare advancements with significant risks of infection (organ transplants, cancer therapy) [10]. The balance between the bacterial load and resistance against infection represents the major factor responsible for SSI. Germs from hospital environments, which are able to survive multiple disinfection, represent a real threat for patients.

American College of Surgeons and Surgical Infection Society set up recommendations for preventing SSI, especially in the era of multi-drug resistance bacterial pathogens, which burdens the patient, the physicians and the hospital [4]. A comprehensive assessment of society's costs and the individual patient attributable to SSIs indicates that the total healthcare burden represents only a tenth of the overall actual value [16]. Regarding SSIs treatment, pharmacological treatment is "a must", initially empiric and then adjusted subsequent to antibiogram analysis, with or without surgical treatment (drainage, debridement, per secundam suture, or vacuum-assisted closure - VAC). Multiple reviews demonstrated that the silver-nylon dressings are associated with decreased SSI and shorter periods of hospitalization. Negative pressure reduces the fluid accumulation and the frequency of dressing changes to only 3 - 5 days [29, 36].

Noting the rise of Methicillin-resistant Staphylococcus aureus (MRSA) prevalence, which developed as hospital-acquired bacteria, to a common communityacquired organism, affecting any person, at any stage of life, it concerns to see other MDR germs following a similar trajectory. A recent report estimated that by 2050 approximately 10 million people per year would die from antibiotic-resistance infections [5].

Therefore, the aim of our study was to investigate the resistance pattern of the microorganisms located in post-operative dehiscence sites treated with VAC in an emergency hospital from Bucharest, Romania.

\section{Materials and Methods}

\section{Study design}

The study retrospectively analysed patients' data that underwent surgery in "Elias" University Emergency Hospital, Bucharest, Romania, from January 2018 to November 2020. Medical records were examined from four surgical departments: reconstructive plastic surgery, obstetrics and gynaecology, neurosurgery and vascular surgery. We obtained for each patient, sociodemographic information, regarding sex, age and previous hospitalization.

The study population comprised hospitalized patients diagnosed with surgical site dehiscence, during this period, with two eligible criteria: (i) single germ infection of the surgical site; (ii) VAC treatment in cases with failure of per secundam suture.
Multiple germ infections on the surgical site represented an exclusion criterion.

92 patients met the inclusion criteria and were enrolled in the study. Due to the retrospective nature of the study, informed consent was not deemed necessary. All the patient data was anonymized and de-identified before analysis. The Ethics Committee of "Elias" Emergency University Hospital has approved the study design.

Sample size and Sampling Technique

Once the surgeon confirmed the failure of the per secundam suture, wound secretions were aseptically obtained. Specimens were collected on sterile cotton swabs without contaminating them with skin commensals. The samples were inoculated on Columbia 5\% blood agar, Chocolate agar, CLED agar, Sabouraud agar (all media produced by OXOID Ltd., UK) and incubated for 18 - 24 hours at $37^{\circ} \mathrm{C}$.

After the incubation period, colonies suggestive of pathogenically significant germs were subjected to species identification in the automatic Vitek 2C/Phoenix BD. system or biochemical tests. For identifying both Gram-negative and Gram-positive microorganisms, fluorogenic and chromogenic conventional tests were automatically performed. All the probes were treated uniformly in the hospital's laboratory.

Antimicrobial susceptibility

The isolated colonies were then tested for antimicrobial susceptibility in Vitek 2C/Phoenix BD. automated system or using the disc-diffusion technique and rendered according to the EUCAST standard.

Statistical analysis

Data were analysed using Microsoft Excel software (version 2019, Microsoft Corporation, Redmond, WA, USA), applying simple descriptive statistics and percentages for certain variables.

\section{Results and Discussion}

The study population's mean age was 65 years (ages from $40-86)$ and the majority of the patients were males $(58.69 \%)$, as the literature described so far. $40.21 \%$ of the patients were already diagnosed as diabetics with altered perioperative blood glucose and $67.5 \%$ had a high body mass index (>25). The mean duration of hospital staying was 30 days (5 - 98 days). The patients enrolled benefited from both pharmacological and surgical treatment: empirical broad-spectrum antibacterial therapy, adjusted following the antibiogram analysis and suture of the surgical dehiscence site with subsequent failure, resorting to VAC treatment.

The looming danger of complicated SSI associated with microbial resistance is persuasive, underscoring the need to implement a set of measures ushering to rational antibiotic therapy. It must be based on an adequate selection of antibacterial agents, a relevant duration of their administration and a suitable route of administration. The proper identification of the 
bacterial pathogen, assessing the germ's prevalence and their resistance to antibiotics is the basis for developing local guidelines for initial antibiotic therapy [30]. From a total of 92 samples, E. coli $(18.47 \%)$ was the most common organism isolated, followed by Pseudomonas aeruginosa (16.30\%) and Enterococcus faecalis (15.21\%), as shown in Table I.

Table I

Distribution pattern of bacterial isolates and MDR

germs

\begin{tabular}{|c|c|c|c|}
\hline Isolated bacteria & $\mathbf{n}$ & $\%$ & MDR n (\%) \\
\hline Acinetobacter baumannii & 7 & 7.60 & $7(100 \%)$ \\
\hline Corynebacterium striatum & 2 & 2.17 & $2(100 \%)$ \\
\hline Enterobacter cloacae & 1 & 1.08 & 0 \\
\hline Enterococcus faecalis & 14 & 15.21 & 0 \\
\hline Enterococcus faecium & 4 & 4.34 & 0 \\
\hline Enterococcus spp & 1 & 1.08 & 0 \\
\hline Escherichia coli & 17 & 18.47 & $13(76.47 \%)$ \\
\hline Klebsiella oxytoca & 1 & 1.08 & 0 \\
\hline Klebsiella pneumoniae & 9 & 9.78 & $8(88.88 \%)$ \\
\hline Morganella morganii & 1 & 1.08 & 0 \\
\hline Proteus mirabilis & 7 & 7.60 & $3(42.85 \%)$ \\
\hline Pseudomonas aeruginosa & 15 & 16.30 & $5(33.33 \%)$ \\
\hline Serratia marcescens & 2 & 2.17 & 0 \\
\hline Staphylococcus aureus & 6 & 6.52 & $4(66.66 \%)$ \\
\hline Staphylococcus aureus MRSA & 1 & 1.08 & $1(100 \%)$ \\
\hline \begin{tabular}{|l|} 
Staphylococcus spp \\
\end{tabular} & 2 & 2.17 & $2(100 \%)$ \\
\hline Achromobacter xylosoxidans & 1 & 1.08 & - \\
\hline Alcaligenes faecalis & 1 & 1.08 & - \\
\hline Total & 92 & 100 & $45(48.91 \%)$ \\
\hline
\end{tabular}

A study reviewing surveillance of SSI from hospitalized patients and also from the out-patient department reported isolated germs as Acinetobacter baumannii, E. Coli and Klebsiella (from hospitalized patients) and E. Coli and Pseudomonas aeruginosa (from the outpatient department) [6]. 883 germs isolated from SSIs in a study from Japan encompassed E. faecalis (19.3\%), S. aureus $(18.1 \%)$, E. coli $(17.2 \%)$ and P. aeruginosa (15.4\%) [43].

A recent report from 12 hospitals in Ethiopia collected biological specimens from SSIs, and the most common germ isolated was E. coli (23.1\%), followed by multidrug resistant Acinetobacter species. Pan-antibiotic resistance among $E$. coli was about $12.5 \%$ and among Acinetobacter species, $34.8 \%$ [15].

Regarding MDR (multi-drug resistant) pathogens in our study, the analysed data highlighted: 13/17 E. Coli samples (76.47\%), 7/7 of Acinetobacter baumannii, 5/15 of Pseudomonas aeruginosa (33.33\%), 8/9 of Klebsiella pneumoniae (88.88\%), 3/7 of Proteus mirabilis (42.86\%), 4/6 of Staphylococcus aureus (66.66\%), 1 Staphylococcus MRSA, 2/2 Corynebacterium striatum and 2/2 of Staphylococcus spp. We also encountered two types of pathogens (Achromobacter xylosoxidans and Alcaligenes faecalis) with no standardized antibiogram in our laboratory. The distribution of germs and MDR strains are presented in Table I. Our results are consistent with Hedaoo et al., the most frequent pathogens were Klebsiella spp. (24\%), S. aureus (20\%), E. coli (15\%) and P. aeruginosa (13\%) [25]. A cohort in the Czech Republic, evaluating infected wounds, raised the antibiotic resistance topic exposing the alarming trend of increasing numbers of MDR strains [30]. The analysed data in our study did not meet panantibiotic resistance.

E. coli showed the highest resistance to cephalosporins (76.47\% ceftazidime, $64.70 \%$ cefuroxime and $41.17 \%$ ceftriaxone), fluoroquinolones (64.70\% levofloxacin) and aminopenicillins ( $82.35 \%$ to ampicillin). The literature reports $E$. coli as one of the most common pathogens isolated from SSIs [6].

In a study from Ethiopia, the resistance rates for $E$. coli were described as $83.3 \%$ to cefotaxime (our study registered a lower rate, $35.29 \%$ ), $70.8 \%$ to ceftazidime, $95.8 \%$ - ampicillin, $83.3 \%$ - ceftriaxone and $87.5 \%$ for cefuroxime [15]. Another study from Southern China, which analysed complicated skin and soft infections, pointed out strains of $E$. coli showing resistance to ampicillin (96.15\% in 2009 - 2010 and $100 \%$ in 2011 - 2013), ceftriaxone, ceftazidime and cefepime (each above 80\%) [33]. In Japan, low rates of E. coli susceptibility were reported to sulbactam/ampicillin $(69.7 \%)$, cefazolin $(63.2 \%)$ and ciprofloxacin $(73.0 \%)$ [43].

Overall, we report lower resistance rates for ampicillin, fluoroquinolones and cephalosporins. For E. coli infection, cephalosporines are widely used as a treatment in our hospital, therefore the high rates of resistance. Recent studies have noted a high percentage of gentamicin-resistant $(>60 \%), 3^{\text {rd }}$ cephalosporinresistant $(>50 \%)$ and fluoroquinolone-resistant (> $50 \%)$ E. coli, data also retrieved in our study, except the rates for gentamicin, which were lower, $41.17 \%[25,30]$.

Acinetobacter baumannii proved a high level of resistance (100\%) to amikacin, fluoroquinolones, carbapenems and cotrimoxazole (7/7 samples). Our alarming analysed data is confirmed by other 3 studies $[6,15,24]$. For instance, surveys from Pakistan and India revealed high resistance rates for Acinetobacter species, even pan-antibiotic [7, 42]. A particular aspect of our study is represented by the high sensibility of Acinetobacter to polymyxins (100\%), in contradiction with a current rising trend of Acinetobacter colistinresistant, with high mortality rates [18].

Acinetobacter baumannii is known to be resistant to most available antibiotics, probably due to its characteristic to survive on dry surfaces for weeks that promotes transmission from fomites [15]. Resistance to aminoglycosides is extensively evaluated in studies, showing $81 \%$ to amikacin and $86 \%$ to gentamicin [2]. We found alarmingly higher rates, $100 \%$ resistance to amikacin and $85.71 \%$ to gentamicin.

Analysing susceptibility/resistance rates for Klebsiella pneumoniae, the following concerning data about resistance was noted: amoxicillin/clavulanic acid 
and ceftazidime $88.88 \%$ each, cefotaxime $66.66 \%$, cefuroxime $100 \%$, ampicillin $11.11 \%$; amikacin showed $77.77 \%$ sensibility, ceftazidime/avibactam $55.55 \%$ sensibility and $88.88 \%$ for carbapenems. Other research detected resistance rates to amoxicillin and ampicillin of $100 \%$ each, ceftriaxone $90 \%$, cefotaxime $70 \%$, cefuroxime $60 \%$, ceftazidime $80 \%$ with rates of success to gentamicin $60 \%$, ciprofloxacin $80 \%$, tetracycline $70 \%$ [15]. Rates of high resistance to ampicillin were also found, alongside sulbactam, ceftazidime and gentamicin (> 50\% each) in Southern China, successfully treated with carbapenems [33].

Ampicillin-resistant Klebsiella pneumoniae is infrequent, whereas cefuroxime-resistant Klebsiella shows higher rates (which can be accountable for our single-dose intraoperative antibiotic prophylaxis, therefore the higher rates of resistance). Cefotaxime and ceftazidime resistance rates were far above $50 \%$ each in our study and literature. Susceptibility to carbapenems and aminoglycosides, also sustained by our research, represent a treatment pathway.

The second most prevalent pathogen analysed in our study was represented by Pseudomonas aeruginosa, with the following rates of resistance: piperacillin/ tazobactam, ceftazidime and gentamicin $40 \%$ each, $73.33 \%$ for levofloxacin, $33.33 \%$ for amikacin and carbapenems. Our findings concur with many studies regarding the resistance to gentamicin and cephalosporins [25]. For instance, a recent research evaluated the rates of meropenem-resistant $(24.4 \%)$, ceftazidimeresistant (18.9\%), ciprofloxacin-resistant (31.7\%), piperacillin/tazobactam-resistant $(24.2 \%)$ and gentamicinresistant $(19.7 \%)$ P. aeruginosa, whereas the results in our study were significantly higher (meropenem $33.33 \%$, ceftazidime $40 \%, 73.33 \%$ resistance for levofloxacin, piperacillin/tazobactam $33.33 \%$ and gentamicin 33.33\%) [30].

$33.33 \%$ of our Pseudomonas aeruginosa germs were MDR, a result consistent with recent studies. Due to MDR $P$. aeruginosa higher prevalence, antibiotics such as colistin are revived. Recent studies showed that colistin-resistant $P$. aeruginosa is emerging in different geographical regions due to different treatment strategies [23]. In our study, all Pseudomonas aeruginosa strains tested for colistin were susceptible. Proteus mirabilis, known for HAI, was examined in 7 samples. Three of them were MDR and showed $100 \%$ susceptibility to ceftazidime and carbapenems, with $42.85 \%$ resistance to gentamicin. Resistance to gentamicin was also confirmed in other reports [44]. Proteus mirabilis is the $4^{\text {th }}$ cause of urinary tract infections in women [38] and males [12], and like other germs, their resistance to antimicrobials increases drastically [37]. A recent study evaluated its resistance regarding forming biofilms - stable biofilms mean higher resistance [21]. Studies in Ghana have confirmed the resistance of Proteus mirabilis to cotrimoxazole (81\%) and ampicillin (77\%) [20], different data from ours: cotrimoxazole $71.42 \%$ and ampicillin $28.57 \%$. Regarding ciprofloxacin-resistant $P$. mirabilis, a study revealed a rate of $40 \%$ [31]. We report significantly lower rates, of $14.28 \%$.

Corynebacterium is an underappreciated pathogen that can be found in SSIs. As reviewed previously, it is associated with diabetic foot, also confirmed in our study ( 1 of 2 cases). This pathogen is known as "hard to grow" in laboratories and considered as a contaminated sample when associated with a diabetic foot. Many studies describe our previous understanding of which bacteria cause SSIs as faulty due to culturebased diagnosis limits, especially that they cannot identify biofilms. They raise the importance of modern molecular techniques and discover new Bacteroides as contributors to SSIs [8].

The literature describes Staphylococcus species as dominant in HAI $[4,25]$, but other bacterial pathogens are ready to overtake. Many hospitals developed measures to prevent colonization with preoperative "bundles", adapted to each surgical specialty and patient risk factors. This "bundle" method is a step to decrease SSIs, thus becoming a routine. For example, a colorectal "bundle" reduced SSIs from $4.9 \%$ to $1.6 \%$ after initialization [4].

The lower prevalence of MRSA in this study can be explained by the fact that hospitals differ in facilities and medical care. MRSA infections represent a considerable number of HAI, and literature suggested throughout time vancomycin and linezolid as leading empirical treatment, with favourable outcome [33]. The economic burden is instead appropriate. In 2009 a study underlined that the cost of the antibiotic represents in the case of linezolid $\approx 20 \%$ of the total and $11 \%$ in vancomycin cases [34]. In our study Staphylococcus MRSA was susceptible to vancomycin, gentamicin, levofloxacin and linezolid.

Table II

Gram-negative and Gram-positive germs distribution

\begin{tabular}{|l|l|}
\hline Gram negative (67.39\%) & Gram positive (32.60\%) \\
\hline Achromobacter & Corynebacterium striatum \\
xylosoxidans & Enterococcus faecalis \\
Acinetobacter baumannii & Enterococcus faecium \\
Alcaligenes faecalis & Enterococcus spp \\
Enterobacter cloacae & Staphylococcus aureus \\
Escherichia coli & Staphylococcus aureus \\
Klebsiella oxytoca & MRSA \\
Klebsiella pneumoniae & Staphylococcus spp \\
Morganella morganii & \\
Proteus mirabilis & \\
Pseudomonas aeruginosa & \\
Serratia marcescens & \\
\hline
\end{tabular}

The current literature reflects Gram-negative and anaerobic bacteria's predominance in SSIs [29, 35], also confirmed by our study. Table II presents the distribution of Gram-positive and negative germs from our research: 7 Gram-positive (30 isolates) and 11 
Gram-negative (62 isolates). Gram-negatives can survive on fomites for months. Acinetobacter is found mainly in Intensive Care Units [22].

We report as the most effective antibacterial agents against Gram-positive: vancomycin, gentamicin and linezolid. This data was also confirmed by other studies [27]. 36/62 (58.06\%) Gram-negative pathogens were MDR Colistin and relatively gentamicin and ciprofloxacin were effective antibiotics against Gram-negative pathogens associated with SSIs, consistent with other studies [15].

Gentamicin proved to be a relatively good option for some pathogens in our study (> 50\% rate of susceptibility). We acknowledge a susceptibility rate of $58.82 \%$ for $E$. coli (10/17 samples), $92.85 \%$ for Enterococcus faecalis (13/14 samples), Proteus mirabilis (57.16\%; 4/7), Pseudomonas aeruginosa (60\%; 9/15), $100 \%$ to Staphylococcus aureus, Staphylococcus aureus MRSA and Staphylococcus spp. Klebsiella pneumoniae had a lower rate of susceptibility to gentamicin (33.33\%; 3/9) and Acinetobacter baumannii proved highly resistant $(85.71 \%$; 6/7 samples). Safe to say, gentamicin is still a good option for Gram-positive germs, not so good on MDR germs and preferably not as the primary treatment on Gram-negative germs. Carbapenems showed $100 \%$ resistance in the case of Acinetobacter baumannii (7/7 samples). Still, we report $100 \%$ susceptibility for $E$. coli (17/17 samples) and Proteus mirabilis (7/7), 88.88\% for Klebsiella pneumoniae (8/9), 66.66\% in the case of Pseudomonas aeruginosa (10/15). Data analysed suggest carbapenems as a valid option, even in some MDR germs infections, but fell as an option for Acinetobacter baumannii, as multiple studies raised awareness. For Acinetobacter baumannii, colistin represents in our study a stain of hope in treating this MDR germ infections, data consistent with other studies [1, 19]. Also, we found susceptibility in all samples of Pseudomonas aeruginosa tested for colistin.

Linezolid is a capable antimicrobial agent for MRSA and spp., Staphylococcus aureus, Corynebacterium striatum, Enterococcus faecalis and Enterococcus spp, which showed susceptibility in all samples tested in our study, consistent with the literature $[27,33]$. Cephalosporines (different classes) proved a low rate of susceptibility for E. coli $(11.76 \%)$ and Klebsiella pneumoniae (11.11\%), but still susceptible for Proteus mirabilis (100\%), Serratia marcescens (100\%; 2/2 samples), Morganella morganii (1/1), Pseudomonas aeruginosa $(60 \%$; 9/15).

Ampicillin showed a low susceptibility rate in the case of $E$. coli (11.76\%; 2/17 samples), but still represents an option in treating Enterococcus faecalis infections $92.85 \%$ rate of susceptibility.

Fluoroquinolones tipped the scales toward resistance to many germs, including Acinetobacter baumannii
(100\%), E. coli $(64.70 \%)$, Klebsiella pneumoniae (77.77\%), Proteus mirabilis (57.14\%), Pseudomonas aeruginosa $(73.33 \%)$. It is still efficient against Staphylococcus aureus (100\%).

Vancomycin was potent in all Enterococcus faecalis, Corynebacterium striatum, Enterococcus faecium, Enterococcus spp, Staphylococcus aureus, MRSA and spp. samples tested for antimicrobial susceptibility. Table III presents the overall germs' susceptibility and resistance to antibiotics - a total of 90 cases, excluding the two germs with non-standardized antibiogram. Vancomycin, linezolid and ceftazidime-avibactam rank in the first place with $100 \%$ susceptibility, the last two with low testing rates. The successive positions are occupied by colistin (94.73\%), ertapenem $(92.10 \%)$, meropenem $(78.33 \%)$ and amikacin $(74.07 \%)$. Considering the percentage of tested/non-tested antibiotics for these pathogens, we cannot disregard gentamicin with only a $63.63 \%$ susceptibility rate. However, it was tested in all, but 2 of the 90 cases, which raises it among the top. Third-generation cephalosporins display an increasing resistance rate $(68.96 \%$ for cefuroxime) and levofloxacin $(60.60 \%)$ with a $74.44 \%$ testing quota. The susceptibility for colistin $(94.73 \%)$ and linezolid $(100 \%)$ is very reassuring. Still, these were tested for few pathogens $-21.11 \%$ for colistin and $13.33 \%$ for linezolid. As described in the literature and stated in this study, they remain a successful HAI tool, as "last resort" antibiotics. We must not forget that the price of 1 vial of colistin is around 24\$ [46], while an intravenous treatment course with linezolid is about $\$ 537$ for a supply of $3000 \mathrm{~mL}$ [46].

Knowledge of bacterial patterns and their antibiotic susceptibility is required in each medical field. SSIs are a reality of many interventions, complicating the post-operative evolution and demanding a straightforward solution. The time-lapse between collecting the specimens from the surgical sites and obtaining the germ species and the antimicrobial pattern must be covered with a therapeutic agent. An efficient treatment involves comprehension of the local microbial resistance to antibiotics. To our understanding, this is the first study to analyse the spectrum and antibiotic susceptibility of germs colonizing surgical sites dehiscence in Romania.

Bacteria have the ability to form biofilms, and through it, can exert antimicrobial resistance alongside other mechanisms. It produces an extracellular polymeric matrix that encases surface-attached bacteria. This biofilm's main characteristic is the increased resistance towards a wide range of stressors (the immune system, disinfectants and antibiotics). An essential mechanism between biofilm bacteria and free-living planktonic bacteria is persistence - a transient tolerance state in which the antibiotic resilience is not genetic, but persists within a susceptible population $[5,28,41]$. 
Table III

The susceptibility profiles of the microorganisms studied

\begin{tabular}{|l|c|c|c|c|c|}
\hline \multirow{2}{*}{ Antibiotics } & \multicolumn{2}{|c|}{ Sensitive } & \multicolumn{2}{c|}{ Resistant } & Not tested \\
\cline { 2 - 6 } & $\mathbf{n}$ & $\mathbf{\%}$ & $\mathbf{n}$ & $\mathbf{\%}$ & $\mathbf{n}(\mathbf{\%})$ \\
\hline Amikacin & 40 & $\mathbf{7 4 . 0 7 \%}$ & 14 & $25.92 \%$ & $36(40 \%)$ \\
\hline Amoxicillin-clavulanic acid & 14 & $41.17 \%$ & 20 & $\mathbf{5 8 . 8 2 \%}$ & $56(62.22 \%)$ \\
\hline Ampicillin & 21 & $51.21 \%$ & 20 & $48.78 \%$ & $49(54.44 \%)$ \\
\hline Cefotaxime & 2 & $14.28 \%$ & 12 & $\mathbf{8 5 . 7 1 \%}$ & $76(84.44 \%)$ \\
\hline Ceftazidime & 27 & $50 \%$ & 27 & $50 \%$ & $36(40 \%)$ \\
\hline Ceftazidime-avibactam & 5 & $\mathbf{1 0 0 \%}$ & 0 & $0 \%$ & $85(94.44 \%)$ \\
\hline Ceftriaxone & 9 & $50 \%$ & 9 & $50 \%$ & $72(80 \%)$ \\
\hline Cefuroxime & 9 & $31.03 \%$ & 20 & $\mathbf{6 8 . 9 6 \%}$ & $61(67.77 \%)$ \\
\hline Ciprofloxacin & 2 & $18.18 \%$ & 9 & $\mathbf{8 1 . 8 1 \%}$ & $79(87.77 \%)$ \\
\hline Colistin & 18 & $\mathbf{9 4 . 7 3 \%}$ & 1 & $5.26 \%$ & $71(78.88 \%)$ \\
\hline Co-trimoxazole & 26 & $49.05 \%$ & 27 & $50.94 \%$ & $37(41.11 \%)$ \\
\hline Ertapenem & 35 & $\mathbf{9 2 . 1 0 \%}$ & 3 & $7.89 \%$ & $52(57.77 \%)$ \\
\hline Gentamicin & 56 & $63.63 \%$ & 32 & $\mathbf{3 6 . 3 6 \%}$ & $\mathbf{2}(\mathbf{2 . 2 2 \% )}$ \\
\hline Imipenem & 24 & $64.86 \%$ & 13 & $35.13 \%$ & $53(58.88 \%)$ \\
\hline Levofloxacin & 26 & $39.39 \%$ & 40 & $\mathbf{6 0 . 6 0 \%}$ & $24(26.66 \%)$ \\
\hline Linezolid & 12 & $\mathbf{1 0 0 \%}$ & 0 & 0 & $78(86.66 \%)$ \\
\hline Meropenem & 47 & $\mathbf{7 8 . 3 3 \%}$ & 13 & $21.66 \%$ & $30(33.33 \%)$ \\
\hline Minocycline & 5 & $71.42 \%$ & 2 & $28.57 \%$ & $83(92.22 \%)$ \\
\hline Moxifloxacin & 0 & 0 & 2 & $100 \%$ & $88(97.77 \%)$ \\
\hline Oxacillin & 1 & $12.5 \%$ & 7 & $87.5 \%$ & $82(91.11 \%)$ \\
\hline Penicillin & 0 & 0 & 2 & $\mathbf{1 0 0 \%}$ & $88(97.77 \%)$ \\
\hline Piperacillin-tazobactam & 9 & $60 \%$ & 6 & $40 \%$ & $75(83.33 \%)$ \\
\hline Rifampicin & 8 & $80 \%$ & 2 & $20 \%$ & $80(88.88 \%)$ \\
\hline Teicoplanin & 19 & $100 \%$ & 0 & 0 & $71(78.88 \%)$ \\
\hline Tetracycline & 0 & 0 & 2 & $100 \%$ & $88(97.77 \%)$ \\
\hline Tigecycline & 10 & $76.92 \%$ & 3 & $23.07 \%$ & $77(85.55 \%)$ \\
\hline Tobramycin & 3 & $50 \%$ & 3 & $50 \%$ & $84(93.33 \%)$ \\
\hline Vancomycin & 26 & $\mathbf{1 0 0 \%}$ & 0 & 0 & $64(71.11 \%)$ \\
\hline & & & & & \\
\hline
\end{tabular}

Clinical diagnosis of SSIs is based on the signs of inflammation at the surgical site (rubor, calor, tumor, dolor) and sometimes fluor (discharge: pus, serous, non-purulent). If the per primam closure fails, the surgical site is dehiscent and prone to infection. The CDC (Centers for Disease Control and Prevention) defines SSIs as an infection within 30 days of surgical intervention [45].

Risk factors for SSI [4, 32, 45]: Regarding the patient: (i) Modifiable: glycaemic control and diabetic status, dyspnoea, alcohol and smoking status, obesity (BMI > $35 \mathrm{~kg} / \mathrm{m}^{2}$ or subcutaneous tissue more generous than $2 \mathrm{~cm}$ ), immunosuppression; (ii) Non-modifiable: age, recent radiotherapy, history of skin and soft tissues infections, sex (males tend to have a higher risk [9]); Regarding the procedure: type of intervention, facility (inadequate ventilation, increased traffic in the operating room and inappropriate sterilization of equipment), longer duration of surgery $[9,11]$.

Long-term blood glucose control and SSIs risk were linked a long time ago, with conflicting results. Recent studies highlighted that glycated haemoglobin is not correlated with SSIs risk, as it was believed. Instead, perioperative hyperglycaemia is significant in diabetics or nondiabetics [4]: serum glucose $110-150 \mathrm{mg} / \mathrm{dL}$ lowers the risk for SSI.
Bacterial resistance is a significant health problem, with alarmingly increasing rates, especially comparing with the gradual decline in antibiotic discoveries, leading to an antimicrobial resistance crisis $[13,26]$. Changes in financial models could translate better the scientific advances of antimicrobial agents into clinically approved antibiotics [17].

Discovering new antibiotics requires financial support and at the same time treating MDR germs implies another financial support. The void in antibiotic discovery should be filled by clinical trials for novel models of antimicrobial agents. As our study highlights, the necessity is overwhelming and treatment options are closing at an unexpected rate. We consider recommendable the current knowledge of SSIs' resistance patterns to ensure proper empirical treatment until the timely therapy according to germ's susceptibility.

\section{Conclusions}

E. coli is primarily responsible for SSIs; $76.46 \%$ are MDR pathogens. Pseudomonas aeruginosa ranked second, with $33.33 \%$ MDR strains. As expected, Acinetobacter baumannii analysed in our study demonstrated $100 \%$ MDR strains, but it displayed high susceptibility to colistin. 
The most effective antibiotics per total number of germs are gentamicin (63.63\%), carbapenems (ertapenem $92.10 \%$ and meropenem $78.33 \%$ ) and amikacin (74.07\%). They represent valuable treatments for $E$. coli and Pseudomonas aeruginosa.

Our study reflects a high number of MDR germs, as literature tries to raise awareness.

\section{Acknowledgement}

This work was financially supported by CNCSISUEFISCDI, Postdoctoral Fellowship Programme PNII-Human Resources, project number 3/28.07.2010, code PD 149/2010.

\section{Conflict of interest}

The authors declare no conflict of interest.

\section{References}

1. Alcántar-Curiel MD, Rosales-Reyes R, Jarillo-Quijada MD, Gayosso-Vázquez C, Fernández-Vázquez JL, Toledano-Tableros JE, Giono-Cerezo S, Garza-Villafuerte P, López-Huerta A, Vences-Vences D, Morfín-Otero R, Rodríguez-Noriega E, López-Álvarez MDR, EspinosaSotero MDC, Santos-Preciado JI, Carbapenem-Resistant Acinetobacter baumannii in three tertiary care hospitals in Mexico: virulence profiles, innate immune response and clonal dissemination. Front Microbiol., 2019; 10: 2116: 1-19.

2. Aliakbarzade K, Farajnia S, Karimi Nik A, Zarei F, Tanomand A, Prevalence of aminoglycoside resistance genes in Acinetobacter baumannii isolates. Jundishapur J Microbiol., 2014; 7(10): e11924: 1-6.

3. Blejan IE, Diaconu CC, Arsene AL, Udeanu DI, Ghica M, Drăgănescu D, Burcea Dragomiroiu GTA, Rădulescu M, Maltezou HC, Tsatsakis AM, Papasavva M, Drakoulis N, Popa DE, Antibiotic resistance in community-acquired pneumonia. A Romanian perspective. Farmacia, 2020; 68(3): 512-520.

4. Ban KA, Minei JP, Laronga C, Harbrecht BG, Jensen EH, Fry DE, Itani KM, Dellinger EP, Ko CY, Duane TM, American College of Surgeons and Surgical Infection Society: Surgical Site Infection Guidelines, 2016 Update. J Am Coll Surg., 2017; 224(1): 59-74.

5. Banin E, Hughes D, Kuipers OP, Editorial: Bacterial pathogens, antibiotics and antibiotic resistance. FEMS Microbiol Rev., 2017; 41(3): 450-452.

6. Bhardwaj N, Khurana S, Kumari M, Malhotra R, Mathur P, Pattern of antimicrobial resistance of Gramnegative bacilli in surgical site infections in in-patients and out-patients at an apex trauma Center: 2013-2016. J Lab Physicians, 2018; 10(4): 432-436.

7. Bibi S, Channa GA, Siddiqui TR, Ahmed W, Pattern of bacterial pathogens in postoperative wounds and their sensitivity patterns. J Surg Pak., 2012; 17(4): 164-167.

8. Bone RC, Balk RA, Cerra FB, Dellinger RP, Fein AM, Knaus WA, Schein RM, Sibbald WJ, Definitions for sepsis and organ failure and guidelines for the use of innovative therapies in sepsis. The ACCP/SCCM Consensus Conference Committee. American College of Chest Physicians/Society of Critical Care Medicine. Chest, 1992; 101(6): 1644-1655.

9. Brown SM, Eremin SR, Shlyapnikov SA, Petrova EA, Shirokova LV, Goldmann D, O'Rourke EJ, Prospective surveillance for surgical site infection in St. Petersburg, Russian Federation. Infect Control Hosp Epidemiol., 2007; 28(3): 319-325.

10. CDC Antibiotic Resistance Threats in the United States, 2019. Atlanta, GA: US Department of Health and Human Services, CDC; 2019; www.cdc.gov/Drug Resistance/Biggest-Threats.html.

11. Cheng H, Chen BP, Soleas IM, Ferko NC, Cameron CG, Hinoul P, Prolonged operative duration increases risk of surgical site infections: A Systematic Review. Surg Infect (Larchmt), 2017; 18(6): 722-735.

12. Chibelean CB, Petca RC, Mareș C, Popescu RI, Enikő B, Mehedinț C, Petca A, A clinical perspective on the antimicrobial resistance spectrum of uropathogens in a Romanian male population. Microorganisms, 2020; 8(6): 848.

13. Calmuschi (Trinc) R, Szasz FA, Trinc S, Robu S, Tutunaru D, Morariu ID, Jompan A, Efficacy of antibiotic approaches in newborns and infants with nasolacrimal duct obstruction. Farmacia, 2019; 67(5): 866-870.

14. Coello R, Charlett A, Wilson J, Ward V, Pearson A, Borriello P, Adverse impact of surgical site infections in English hospitals. J Hosp Infect., 2005; 60(2): 93103.

15. Dessie W, Mulugeta G, Fentaw S, Mihret A, Hassen M, Abebe E, Pattern of bacterial pathogens and their susceptibility isolated from Surgical Site Infections at selected referral hospitals, Addis Ababa, Ethiopia. Int J Microbiol., 2016; 2016: 2418902: 1-9.

16. Dohmen PM, Antibiotic resistance in common pathogens reinforces the need to minimise surgical site infections. J Hosp Infect., 2008; 70(Suppl 2): 15-20.

17. Drăgănescu D, Lupuleasa D, Dumitrescu IB, Dinu Pârvu CE, Ciolan DF, Evidence on e-prescribing systems worldwide. First Romanian results. Farmacia, 2013; 61(2): 353-360.

18. Elham B, Fawzia A, Colistin resistance in Acinetobacter baumannii isolated from critically ill patients: clinical characteristics, antimicrobial susceptibility and outcome. Afr Health Sci., 2019; 19(3): 2400-2406.

19. Evans BA, Hamouda A, Amyes SG, The rise of carbapenem-resistant Acinetobacter baumannii. Curr Pharm Des., 2013; 19(2): 223-238.

20. Feglo PK, Gbedema SY, Quay SNA, Adu-Sarcodie Y, Opoku-Okrah C, Occurrence, species distribution and antibiotic resistance of Proteus isolates: A case study at the Komfo Anokye Teaching Hospital (KATH) in Ghana. Int J Pharma Sci Res (IJPSR.), 2010; 1(9): 347-352.

21. Filipiak A, Chrapek M, Literacka E, Wawszczak M, Ghuszek S, Majchrzak M, Wróbel G, Łysek-Gładysińska M, Gniadkowski M, Adamus-Białek W, Pathogenic factors correlate with antimicrobial resistance among clinical Proteus mirabilis strains. Front Microbiol., 2020; 11: 579389: 1-11.

22. Gelaw A, Gebre-Selassie S, Tiruneh M, Mathios E, Yifru S, Isolation of bacterial pathogens from patients with post-operative surgical site infections and possible sources of infections at the University of Gondar 
Hospital, Northwest Ethiopia. J Environ Occup Sci., 2014; 3(2): 103-108.

23. Goli HR, Nahaei MR, Ahangarzadeh Rezaee M, Hasani A, Samadi Kafil H, Aghazadeh M, Emergence of colistin resistant Pseudomonas aeruginosa at Tabriz hospitals, Iran. Iran J Microbiol., 2016; 8(1): 62-69.

24. Guillamet CV, Kollef MH, How to stratify patients at risk for resistant bugs in skin and soft tissue infections?. Curr Opin Infect Dis., 2016; 29(2): 116-123.

25. Hedaoo J, Rathod V, Paramne A, Bacteriology of surgical site infections and antibiotic susceptibility pattern in isolates of post-operative wound infections. Acad J Surg., 2018; 5(1-2): 16-20.

26. Hutchings MI, Truman AW, Wilkinson B, Antibiotics: past, present and future. Curr Opin Microbiol., 2019; 51: 72-80.

27. Insan NG, Payal N, Singh M, Yadav A, Chaudhary BL, Srivastava A, Post-operative wound infection: bacteriology and antibiotic sensitivity pattern. Int $J$ Cur Res Rev., 2013; 5(13): 74-79.

28. Jamal M, Ahmad W, Andleeb S, Jalil F, Imran M, Nawaz MA, Hussain T, Ali M, Rafiq M, Kamil MA, Bacterial biofilm and associated infections. J Chin Med Assoc., 2018; 81(1): 7-11.

29. Kawakita T, Landy HJ, Surgical site infections after cesarean delivery: epidemiology, prevention and treatment. Matern Health Neonatol Perinatol., 2017; 3: 12: 1-9.

30. Kolar M, Cermak P, Hobzova L, Bogdanova K, Neradova K, Mlynarcik P, Bostik P, Antibiotic resistance in nosocomial bacteria isolated from infected wounds of hospitalized patients in Czech Republic. Antibiotics (Basel), 2020; 9(6): 342: 1-8.

31. Kwiecińska-Piróg J, Skowron K, Zniszczol K, Gospodarek E, The assessment of Proteus mirabilis susceptibility to Ceftazidime and Ciprofloxacin and the impact of these antibiotics at subinhibitory concentrations on Proteus mirabilis biofilms. Biomed Res Int., 2013: 930876: 1-8.

32. Lachiewicz MP, Moulton LJ, Jaiyeoba O, Pelvic surgical site infections in gynecologic surgery. Infect Dis Obstet Gynecol., 2015; 2015: 614950: 1-8.

33. Li X, Chen Y, Gao W, Ouyang W, Wei J, Wen Z, Epidemiology and outcomes of complicated skin and soft tissue infections among inpatients in Southern China from 2008 to 2013. PLoS One, 2016; 11(2): e0149960: 1-13.

34. Nathwani D, Dryden M, Garau J, Early clinical assessment of response to treatment of skin and softtissue infections: how can it help clinicians? Perspectives from Europe. Int J Antimicrob Agents, 2016; 48(2): 127-136.

35. Navarro-San Francisco C, Ruiz-Garbajosa P, Cantón $\mathrm{R}$, The what, when and how in performing and interpreting microbiological diagnostic tests in skin and soft tissue infections. Curr Opin Infect Dis., 2018; 31(2): 104-112.
36. Petca A, Negoita S, Petca RC, Calo O, Sinescu RD, Ether-Based Polyurethane foam for Vacuum-Assisted Closure (VAC) of complicated post-operative abdominal wound dehiscence. Mater Plast., 2020; 57(2): 32-38.

37. Petca RC, Mareș C, Petca A, Negoiță S, Popescu RI, Boț M, Barabás E, Chibelean CB, Spectrum and antibiotic resistance of uropathogens in Romanian females. Antibiotics (Basel), 2020; 9(8): 472: 1-16.

38. Petca RC, Popescu RI, Mares C, Petca A, Mehedintu C, Sandu I, Maru N, Antibiotic resistance profile of common uropathogens implicated in urinary tract infections in Romania. Farmacia, 2019, 67(6): 9941004.

39. Purba AKR, Setiawan D, Bathoorn E, Postma MJ, Dik JH, Friedrich AW, Prevention of surgical site infections: a systematic review of cost analyses in the use of prophylactic antibiotics. Front Pharmacol., 2018; 9: 776: 1-18.

40. Semsarzadeh NN, Tadisina KK, Maddox J, Chopra K, Singh DP, Closed incision negative-pressure therapy is associated with decreased surgical-site infections: a meta-analysis. Plast Reconstr Surg., 2015; 136(3): 592-602.

41. Sharma D, Misba L, Khan AU, Antibiotics versus biofilm: an emerging battleground in microbial communities. Antimicrob Resist Infect Control, 2019; 8: $76: 1-10$.

42. Sikka R, Mann JK, Deep, Vashist MG, Chaudhary U, Deep A, Prevalence and antibiotic sensitivity pattern of bacteria isolated from nosocomial infections in a surgical ward. Ind J Clin Pract., 2012; 22(10): 519-525.

43. Takesue Y, Kusachi S, Mikamo H, Sato J, Watanabe A, Kiyota H, Iwata S, Kaku M, Hanaki H, Sumiyama Y, Kitagawa Y, Mizuguchi T, Ambo Y, Konosu M, Ishibashi K, Matsuda A, Hase K, Harihara Y, Okabayashi K, Seki S, Hara T, Matsui K, Matsuo Y, Kobayashi M, Kubo S, Uchiyama K, Shimizu J, Kawabata R, Ohge H, Akagi S, Oka M, Wakatsuki T, Suzuki K, Okamoto K, Yanagihara K, Antimicrobial susceptibility of pathogens isolated from surgical site infections in Japan: Comparison of data from nationwide surveillance studies conducted in 2010 and 2014-2015. J Infect Chemother., 2017; 23(6): 339-348.

44. Tumbarello M, Sanguinetti M, Montuori E, Trecarichi EM, Posteraro B, Fiori B, Citton R, D'Inzeo T, Fadda G, Cauda R, Spanu T, Predictors of mortality in patients with bloodstream infections caused by extendedspectrum-beta-lactamase-producing Enterobacteriaceae: importance of inadequate initial antimicrobial treatment. Antimicrob Agents Chemother., 2007; 51(6): 19871994.

45. World Union of Wound Healing Societies (WUWHS) Consensus Document. Surgical wound dehiscence: improving prevention and outcomes. Wounds International, 2018; www.woundsinternational.com.

46. www.drugs.com/price-guide. 